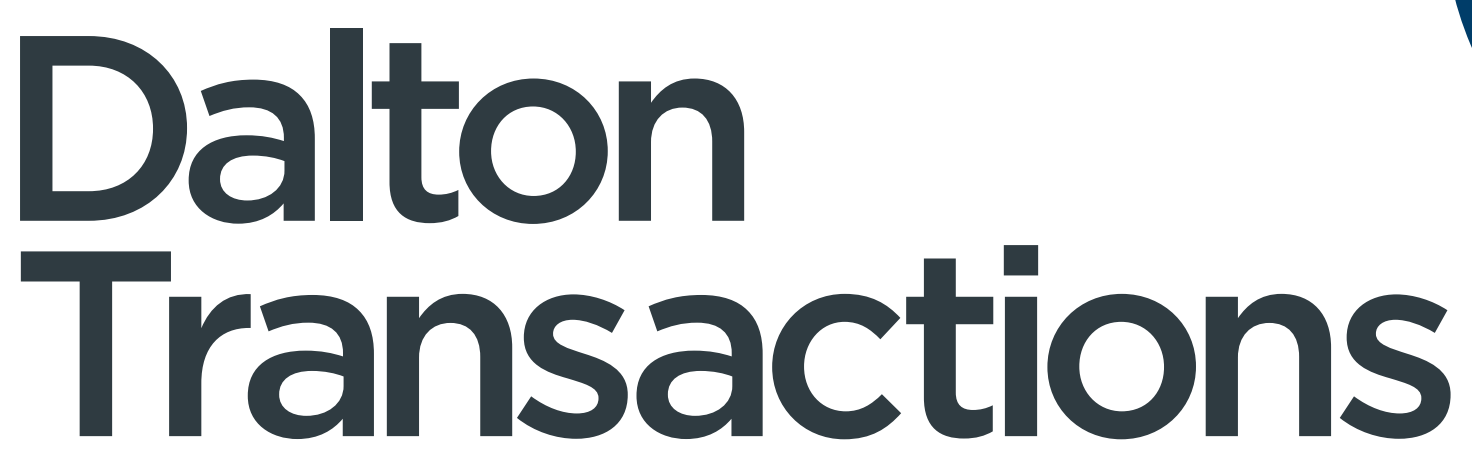

An international journal of inorganic chemistry

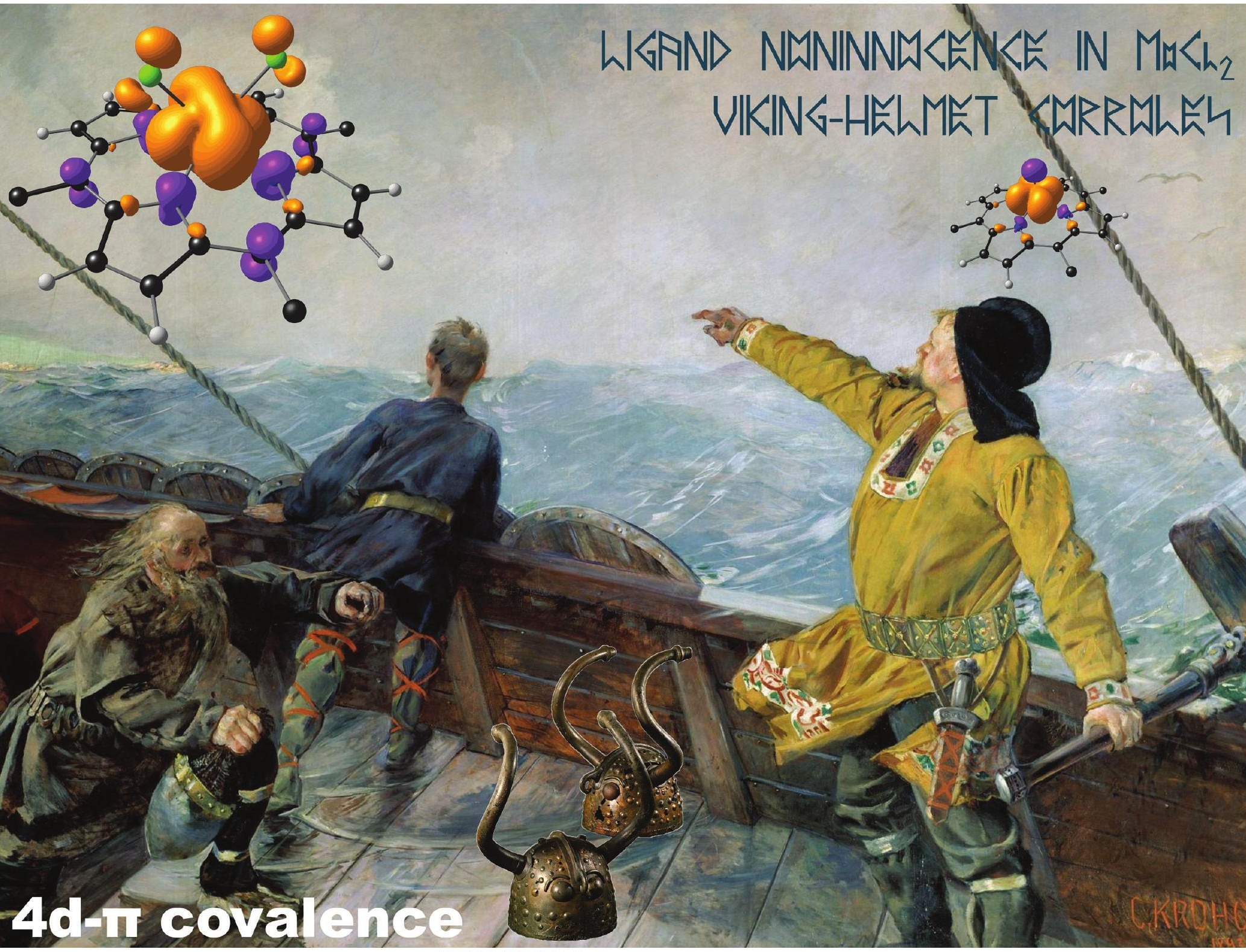

ISSN 1477-9226

ROYAL SOCIETY $\because$ OF CHEMISTRY

\section{PAPER}

Abraham B. Alemayehu, Abhik Ghosh et al.

Heavy-element-ligand covalence: ligand noninnocence in molybdenum and tungsten Viking-helmet Corroles

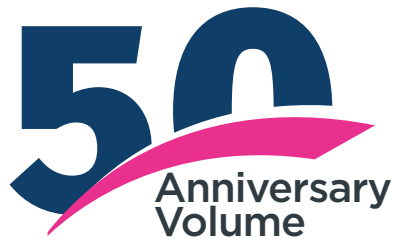




\section{A) Check for updates}

Cite this: Dalton Trans., 2021, 50 12843

Received 15th June 2021, Accepted 19th August 2021

DOI: 10.1039/d1dt01970h

rsc.li/dalton

\title{
Heavy-element-ligand covalence: ligand noninnocence in molybdenum and tungsten Viking-helmet Corroles $\uparrow$
}

\author{
Hugo Vazquez-Lima, a,b Jeanet Conradie, (D) a,c Martin A. L. Johansen, ${ }^{a}$ \\ Stian Rølvaag Martinsen, (D) a Abraham B. Alemayehu*a and Abhik Ghosh (D) *a
}

\begin{abstract}
Extensive DFT calculations with several exchange-correlation functionals indicate that molybdenumdichlorido Viking helmet corroles are noninnocent with significant $\mathrm{Mo}^{\mathrm{IV}}$-corrole ${ }^{-2-}$ character. The effect is mediated by a $\mathrm{Mo}(4 \mathrm{~d})$ - $\operatorname{corrole}(\pi)$ orbital interaction similar to that postulated for $\mathrm{MnCl}, \mathrm{FeCl}$ and $\mathrm{FeNO}$ corroles. The effect also appears to operate in tungsten-dichlorido corroles but is weaker relative to that for Mo. In contrast, MoO triarylcorroles do not exhibit a significant degree of corrole radical character. Furthermore, the Soret absorption maxima of a series of $\mathrm{MoCl}_{2}$ tris(para-X-phenyl)corrole derivatives were found to redshift dramatically with increasing electron-donating character of the para substituent $X$, essentially clinching the case for a noninnocent macrocycle in $\mathrm{MoCl}_{2}$ corroles.
\end{abstract}

\section{Introduction}

Over a half-century ago, the Danish chemist C. K. Jørgensen defined a noninnocent ligand as one that leaves the oxidation state of the coordinated atom uncertain or debatable. ${ }^{1}$ For ligands involving extended $\pi$-systems, ligand noninnocence typically entails partial oxidation and reduction of the $\pi$-system, i.e., $\pi$-radical character. ${ }^{2,3}$ The phenomenon has been widely studied for $3 \mathrm{~d}$ transition metals, perhaps most famously for the $\mathrm{C}-\mathrm{H}$-activating Compound I intermediate of cytochrome P450, ${ }^{4,5}$ but far less so for $4 \mathrm{~d}, 5 \mathrm{~d}$, and f-element systems. ${ }^{6-8}$ The rarity of well-characterized, noninnocent $4 \mathrm{~d}$ and $5 \mathrm{~d}$ metal systems reflects in part the rarity of stable, paramagnetic complexes involving these elements (which in turn reflects their preference for low-spin states), robbing magnetic resonance methods such as paramagnetic NMR and EPR spectroscopy of the ability to characterize the phenomenon by probing molecular spin densities..$^{9-16}$ It is against this backdrop that we have chosen to reexamine paramagnetic molybdenum ${ }^{17}$ and tungsten ${ }^{18}$ dichlorido "Viking-helmet" corroles

\footnotetext{
${ }^{a}$ Department of Chemistry, UiT - The Arctic University of Norway, N-9037 Tromsø, Norway.E-mail: abraham.alemayehu@uit.no,abhik.ghosh@uit.no

${ }^{b}$ Centro de Química, Instituto de Ciencias, Universidad Autónoma de Puebla, Edif. IC9, CU, San Manuel, 72570 Puebla, Puebla, Mexico

${ }^{c}$ Department of Chemistry, University of the Free State, P.O. Box 339, Bloemfontein, 9300, South Africa

$\dagger$ Electronic supplementary information (ESI) available. See DOI: 10.1039/ d1dt01970h
}

with density functional theory methods for possible signs of a noninnocent corrole (Scheme 1; see also Notes).

In recent years, metallocorroles have provided many examples of well-characterized noninnocent systems. ${ }^{19-22}$ Key examples include $\mathrm{MnCl},{ }^{23} \mathrm{FeCl},{ }^{9-15} \mathrm{FeNO}^{24-27} \mathrm{Fe}_{2}(\mu-\mathrm{O}),{ }^{28} \mathrm{Co}-$ $\mathrm{py}^{29} / \mathrm{DMSO}^{30}$ (py = pyridine), Co- $\mathrm{PPh}_{3},{ }^{31}$ and $\mathrm{Cu}^{32-40}$ corrole derivatives. It is worth noting that all these involve first-row transition metals. In contrast, the overwhelming majority of $4 \mathrm{~d}$ and $5 \mathrm{~d}$ transition metal corroles are thought to involve an innocent corrole macrocycle. ${ }^{20,41}$ That said, both $\mathrm{Pt}^{\mathrm{IV}}$-arylcorrole $^{3-}$ (ref. 42) and $\mathrm{Pt}^{\mathrm{IV}}$-aryl-corrole ${ }^{\cdot 2-}$ derivatives ${ }^{43}$ are known, as are simple $\mathrm{Zn}^{\mathrm{II}}$-corrole ${ }^{\cdot 2-}$ radical species; ${ }^{44}$ the metal oxidation states in these systems, however, are not in doubt so these, according to the definition above, do not qualify as noninnocent. Silver corroles present a more interest-
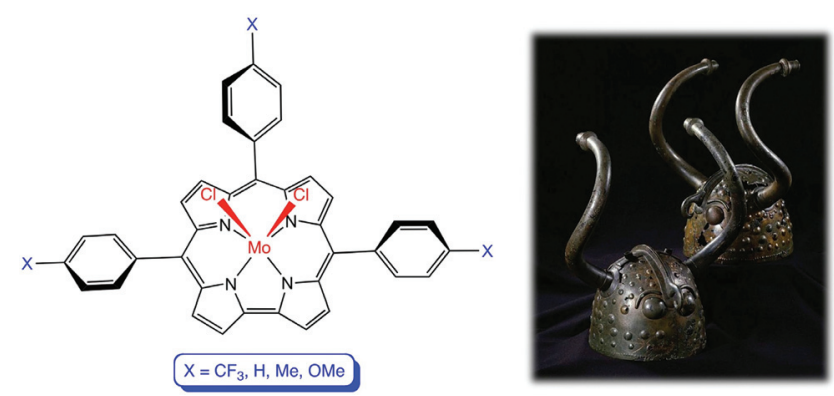

Scheme 1 Molybdenum-dichlorido "Viking-helmet" corroles. Right: Bronze Age horned helmets from Veksø, Denmark. 
ing scenario: while simple, relatively planar $\mathrm{Ag}$ triarylcorroles, like their Au counterparts, are thought to be innocent, highly saddled Ag $\beta$-octabromo-meso-triarylcorroles, like their $\mathrm{Cu}$ counterparts, ${ }^{32-40}$ are thought to harbor noninnocent macrocycles. ${ }^{45,46}$

The assignment of an innocent or noninnocent description for a given system can be a tricky proposition and misassignments abound in the literature. In our own work on metallocorroles, we have regularly used half a dozen techniques as physicochemical probes of ligand noninnocence and advocated the use of at least three such probes for a credible electronicstructural assignment. ${ }^{22}$ Herein, we report three lines of evidence strongly supporting a noninnocent description for $\mathrm{MoCl}_{2}$ Viking-helmet corroles: (i) an existing X-ray structure, whose implications for ligand noninnocence have not been realized until now, and optimized DFT geometries, (ii) DFT spin density profiles, and (iii) in situ electronic absorption spectra.

\section{Results and discussion}

\section{Molecular structure}

High-quality X-ray structures commonly signal a noninnocent corrole in the form of characteristic bond length alternations within and around the bipyrrole unit of the macrocycle. ${ }^{22}$ As it happens, the reported X-ray structure of $\mathrm{Mo}\left[\mathrm{T} p \mathrm{OCH}_{3} \mathrm{PC}\right] \mathrm{Cl}_{2}$ [where $\mathrm{T} \mathrm{OCH}_{3} \mathrm{PC}^{3-}$ refers to the trianion of meso-tris(4-methoxyphenyl)corrole; CSD code: NEMMAW; Fig. 1] is indeed of
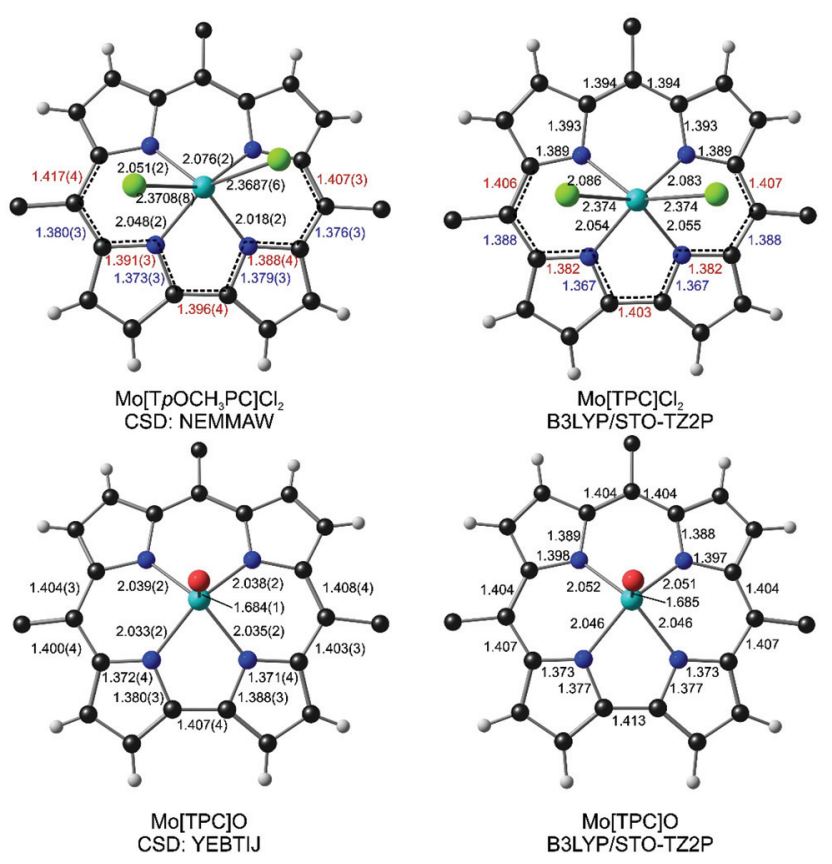

Fig. 1 Selected distances in the X-ray structures of $\mathrm{Mo}\left[\mathrm{TpOCH} \mathrm{PC}_{3} \mathrm{Cl}_{2}\right.$ and Mo[TPC]O and the DFT (B3LYP/STO-TZ2P) optimized geometries of $\mathrm{Mo}[\mathrm{TPC}] \mathrm{Cl}_{2}$ and $\mathrm{Mo}[\mathrm{TPC}] \mathrm{O}$. Parts of the corrole skeleton exhibiting bond length alternation are indicated with dashed lines and alternate longer and shorter bonds therein are indicated in red and blue, respectively.

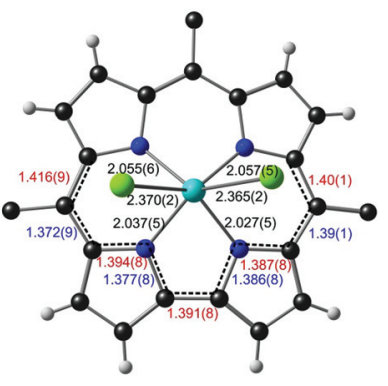

CSD: WUNZUC

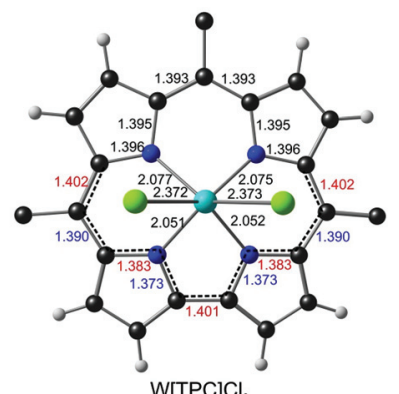

B3LYPISTO-TZ2P

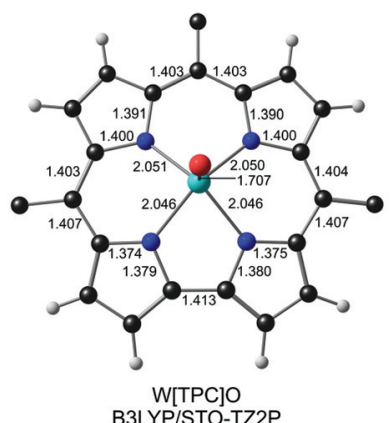

B3LYP/STO-TZ2P

Fig. 2 Selected distances in the X-ray structure of a $\mathrm{WCl}_{2}$-triarylcorrole and the DFT (B3LYP/STO-TZ2P) optimized geometry of $\mathrm{Mo}[\mathrm{TPC}] \mathrm{Cl}_{2}$. Parts of the corrole skeleton exhibiting bond length alternation are indicated with dashed lines and alternate longer and shorter bonds therein are indicated in red and blue, respectively.

high quality and shows exactly such a bond length alternation (although the point was not remarked upon in the original report). ${ }^{17}$ Somewhat less clearly, a similar bond length alternation is also observed in the X-ray structure of an electron-rich $\mathrm{WCl}_{2}$-triarylcorrole (CSD: WUNZUC; Fig. 2 ) ${ }^{18}$ In contrast, the $\mathrm{X}$-ray structure of Mo[TPC]O (CSD: YEBTIJ; TPC $^{3-}=$ meso-triphenylcorrolato; Fig. 1) ${ }^{47}$ does not evince a similar bond length alternation, while terminal tungsten-oxo corroles, to our knowledge, have not been reported. Interestingly, while CrO triarylcorroles generally do not exhibit skeletal bond length alternations, ${ }^{48}$ an electron-rich CrO-triarylcorrole with a 10-p-hydroxyphenyl substituent does, emphasizing the subtlety of the matter. ${ }^{49}$

To complement the above crystallographic findings, we carried out scalar-relativistic DFT calculations using the Zeroth Order Regular Approximation (ZORA) to the Dirac equation (as implemented in the ADF program system) and all-electron STO-TZ2P basis sets on four model systems - Mo[TPC $] \mathrm{Cl}_{2}$, $\mathrm{Mo}[\mathrm{TPC}] \mathrm{O}, \mathrm{W}[\mathrm{TPC}] \mathrm{Cl}_{2}$ and $\mathrm{W}[\mathrm{TPC}] \mathrm{O}$ (where TPC = triphenylcorrolato). To derive trustworthy conclusions, we used six exchangecorrelation functionals including the extensively tested, highquality pure functionals OLYP and OPBE, the hybrid functionals B3LYP, TPSSH, and OPBE0, and the range-separated hybrid functional CAM-B3LYP. All beautifully confirmed the crystallographic results and the expected bond length alternations for $\mathrm{Mo}[\mathrm{TPC}] \mathrm{Cl}_{2}$ and the lack of such alternations for $\mathrm{Mo}[\mathrm{TPC}] \mathrm{O}$ (Fig. 1). The calculations also confirmed bond length alternations for $\mathrm{W}[\mathrm{TPC}] \mathrm{Cl}_{2}$ (Fig. 2), but careful examination of 
the optimized geometries showed that the alternations are smaller in magnitude than for $\mathrm{Mo}[\mathrm{TPC}] \mathrm{Cl}_{2}$, potentially indicating a lower degree of corrole ${ }^{\cdot 2-}$ character in the $\mathrm{W}$ case.

\section{Spin density profiles and MO analysis}

All six functionals yielded qualitatively similar spin density profiles (Table 1). For Mo[TPC] $\mathrm{Cl}_{2}$, the Mo Mulliken spin population was found to be 1.10-1.35 (Fig. 3 and Table 1), while a corrole spin population of $\sim-0.3$ was found to be distributed approximately in the form of a porphyrin-like " $\mathrm{a}_{2 \mathrm{u}}$ " radical. The spin density of $\mathrm{W}[\mathrm{TPC}] \mathrm{Cl}_{2}$ (Fig. 4) is qualitatively similar, but displays smaller spatial separation of majority and minority spin $(-0.2$ on the corrole) densities. In contrast, we found minimal evidence for a similar metal $\left(\mathrm{d}_{z^{2}}\right)$-corrole( $\left(\mathrm{a}_{2 \mathrm{u}}\right.$ ") interaction and hence of a corrole radical for $\mathrm{Mo}[\mathrm{TPC}] \mathrm{O}$ and $\mathrm{W}[\mathrm{TPC}] \mathrm{O}$.

It is instructive to interpret the spin density profile of $\mathrm{Mo}[\mathrm{TPC}] \mathrm{Cl}_{2}$ in terms of $\mathrm{Mo}(4 \mathrm{~d})$-corrole $(\pi)$ interactions as reflected in the frontier Kohn-Sham molecular orbitals (MOs), several of which are depicted in Fig. 5. The topology of the spin density on the Mo is consistent with an unpaired electrons in the $\mathrm{d}_{x y}$ orbital $(\mathrm{HOMO}-4,173 \alpha)$ and fractional occupancy of the Mo $4 \mathrm{~d}_{y z}$ (HOMO-3, $174 \alpha$ ) and $4 \mathrm{~d}_{z^{2}}$ orbitals (HOMO-2, $173 \beta$ ), the $\mathrm{z}$ direction being normal to the mean plane of the corrole. Note that the HOMO-2 and HOMO-3 are the majority- and minority-spin correspondents of what is essentially the "porphyrin $\mathrm{a}_{2 \mathrm{u}}$-like" corrole-HOMO. The latter, minority-spin MO is slightly more localized on the corrole than on

Table 1 Mulliken spin populations for selected atoms in $\mathrm{Mo}[\mathrm{TPC}] \mathrm{Cl}_{2}$ for different exchange-correlation functionals. (Note that only half the molecule is effectively symmetry-distinct.)

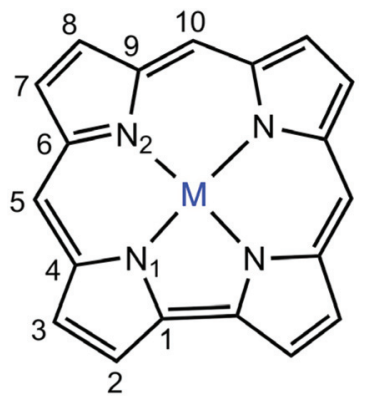

\begin{tabular}{lrrrrrc}
\hline & OLYP & OPBE & B3LYP & TPSSH & OPBE0 & CAM-B3LYP \\
\hline Mo & 1.101 & 1.170 & 1.120 & 1.136 & 1.342 & 1.226 \\
Cl1 & 0.032 & 0.022 & 0.029 & 0.026 & 0.009 & 0.025 \\
C1 & 0.005 & 0.004 & 0.005 & 0.005 & 0.002 & 0.001 \\
C2 & -0.001 & -0.002 & 0.001 & 0.000 & 0.004 & 0.005 \\
C3 & 0.004 & 0.004 & 0.002 & 0.003 & 0.000 & -0.002 \\
C4 & 0.008 & 0.009 & 0.012 & 0.013 & 0.021 & 0.019 \\
C5 & -0.022 & -0.026 & -0.032 & -0.033 & -0.062 & -0.056 \\
C6 & 0.008 & 0.009 & 0.011 & 0.011 & 0.016 & 0.013 \\
C7 & 0.002 & 0.002 & 0.005 & 0.004 & 0.011 & 0.018 \\
C8 & -0.001 & -0.001 & -0.002 & -0.002 & -0.006 & -0.010 \\
C9 & 0.008 & 0.008 & 0.016 & 0.015 & 0.031 & 0.040 \\
C10 & -0.025 & -0.031 & -0.041 & -0.042 & -0.086 & -0.092 \\
N1 & -0.038 & -0.045 & -0.039 & -0.041 & -0.069 & -0.052 \\
N2 & -0.044 & -0.053 & -0.047 & -0.050 & -0.086 & -0.069
\end{tabular}
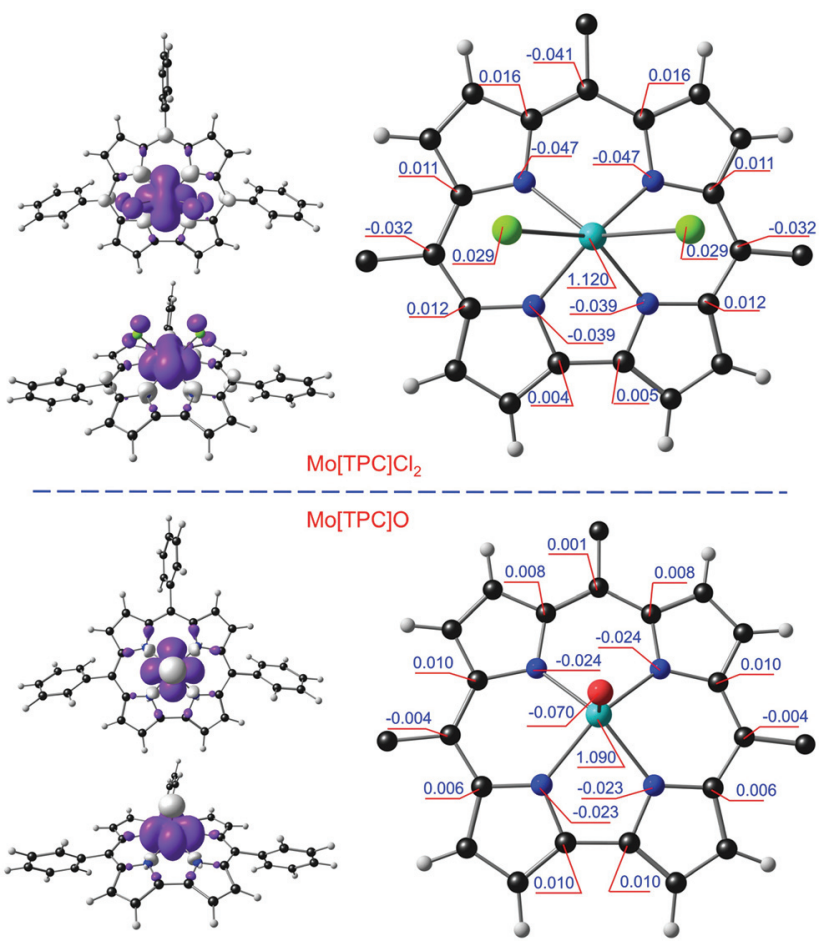

Fig. 3 Top and side views of DFT (B3LYP/STO-TZ2P) spin density plots (contour $=0.002$ e $\AA^{-3}$ ) for $\mathrm{Mo}$ TPC]Cl 2 and Mo[TPC]O. Majority and minority spin densities are indicated in purple and ivory, respectively. Mulliken spin populations are shown for selected atoms.
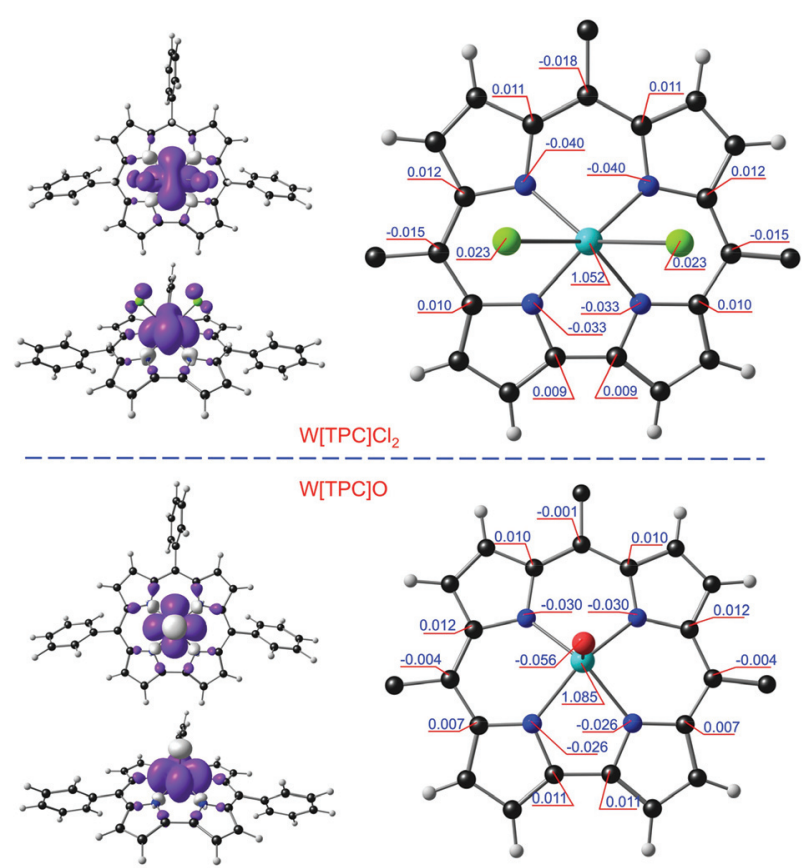

Fig. 4 Top and side views of DFT (B3LYP/STO-TZ2P) spin density plots (contour $=0.002$ e $\AA^{-3}$ ) for $\mathrm{W}[\mathrm{TPC}] \mathrm{Cl}_{2}$ and $\mathrm{W}[\mathrm{TPC}] \mathrm{O}$. Majority and minority spin densities are indicated in purple and ivory, respectively. Mulliken spin populations are shown for selected atoms. 

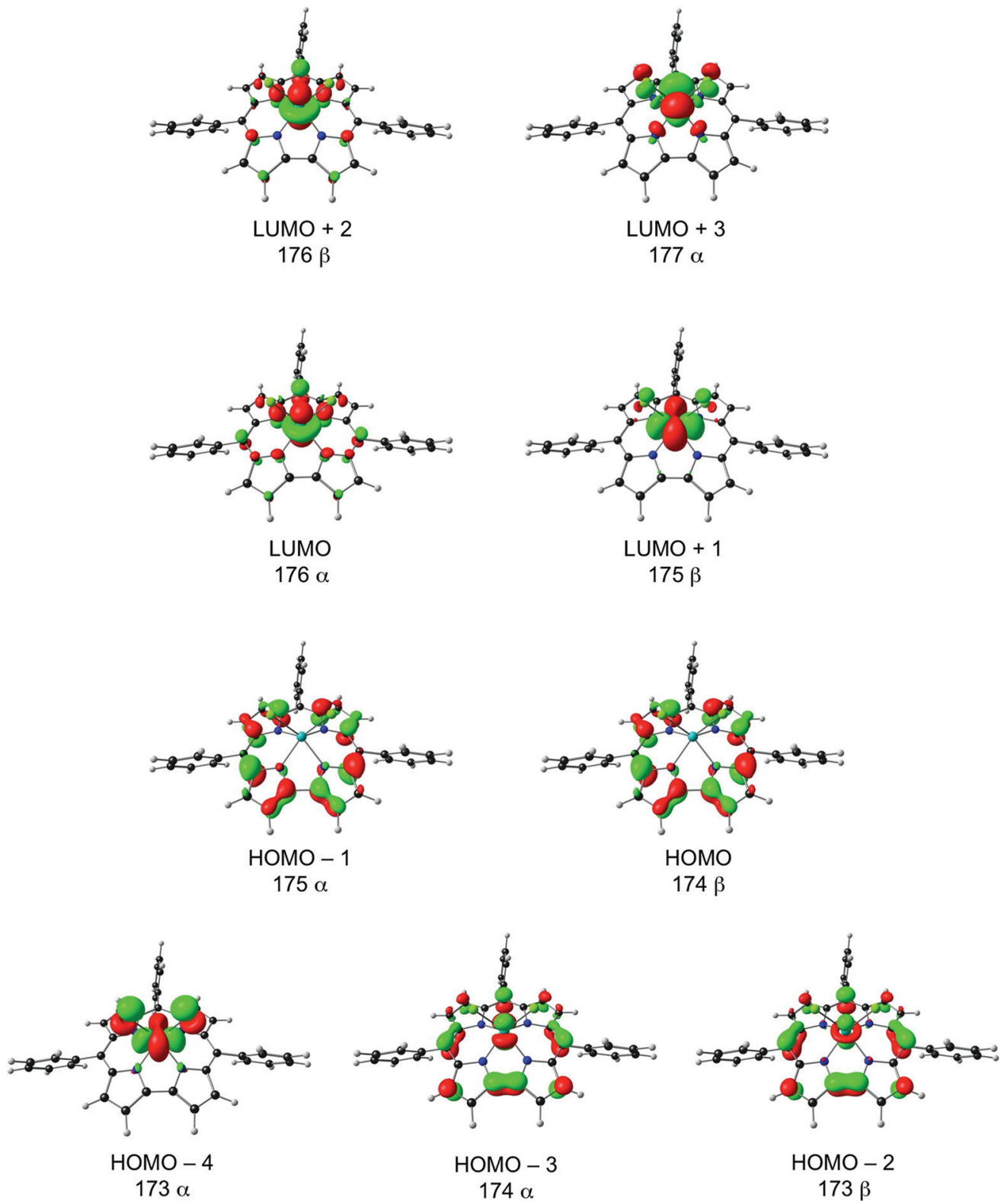

Fig. 5 Selected frontier Kohn-Sham MOs of $\mathrm{Mo}[\mathrm{TPC}] \mathrm{Cl}_{2}$.

the $\mathrm{MoCl}_{2}$ unit, relative to the former, accounting for the net $\mathrm{a}_{2 \mathrm{u}}$-type radical character evident in the molecule's spin density profile (Fig. 3). The $\operatorname{Mo}\left(4 \mathrm{~d}_{z^{2}}\right)$-corrole( " $\mathrm{a}_{2 \mathrm{u}}$ ") interaction evident in the HOMO-2 and LUMO (Fig. 5) is, topologically, exceedingly similar to analogous interactions involving the $3 \mathrm{~d}_{z^{2}}$ orbital in $\mathrm{MnCl}^{23} \mathrm{FeCl}^{10-15} \mathrm{FeNO},{ }^{27}$ and $\mathrm{Co}-\mathrm{PPh}_{3}{ }^{31}$ corroles. Importantly, this picture was fully borne out by an examination of the $4 \mathrm{~d}$-based natural bond orbitals (NBOs) of the molecule.

The electronic-structural difference between $\mathrm{MoCl}_{2}$ and $\mathrm{MoO}$ corroles may be likened to similar differences within $\mathrm{MnCl} / \mathrm{MnPh}$ and $\mathrm{FeCl} / \mathrm{FePh}$ corroles. In each of these cases, a stronger-field ligand (whether strongly $\sigma$-donating like $\mathrm{Ph}$ or both strongly $\sigma$ - and $\pi$-donating like oxo) stabilizes a higher- valent metal center and concomitantly an innocent corrole. A weaker axial ligands such as chloride behaves oppositely, resulting in a noninnocent corrole.

To gain an estimate of the strength of the $\operatorname{Mo}\left(4 \mathrm{~d}_{z^{2}}\right)$ corrole $^{\cdot 2-}$ antiferromagnetic coupling, we optimized the corresponding ferromagnetically-coupled $(S=3 / 2)$ state of $\mathrm{Mo}$ [TPC]O and found its energy to be $\sim 0.9 \mathrm{eV}$ above the ground state (for the B3LYP functional). In stark contrast, the ferromagnetically coupled states of $\mathrm{MnCl}^{23} \mathrm{FeCl}^{10-15}{ }^{15} \mathrm{FeNO},{ }^{27}$ and $\mathrm{Co}-\mathrm{PPh}_{3}{ }^{31}$ corroles were invariably found to occur only a few tenths of an $\mathrm{eV}$ higher in energy relative to the antiferromagnetically-coupled ground state, a testament to much stronger metal-ligand orbital interactions for the heavier transition elements. This result provides a rare 
measure of metal-ligand magnetic coupling for a $4 \mathrm{~d}$ transition metal.

\section{In situ electronic absorption spectroscopy}

The optical spectra of a series of meso-tris( $p$-X-phenyl)corrole (TpXPC) derivatives provide one of the simplest yet most reliable indications of the innocence or otherwise of the corrole macrocycle. $^{22}$ If the Soret maximum is essentially invariant with respect to the electron-donating/withdrawing power of the para substituent $\mathrm{X}$, the metallocorrole series in question may be expected to be innocent. On the other hand, if the Soret band redshifts markedly in response to increasing electron-donating character of $\mathrm{X}$, then the corrole is noninnocent. To apply this optical probe to $\mathrm{MoCl}_{2}$ corroles, we generated a series of $\mathrm{Mo}[\mathrm{T} p \mathrm{XPC}] \mathrm{Cl}_{2}\left(\mathrm{X}=\mathrm{CF}_{3}, \mathrm{H}\right.$, $\mathrm{CH}_{3}$, and $\mathrm{OCH}_{3}$ ) derivatives from the corresponding $\mathrm{MoO}$ complexes and recorded their optical spectra in situ (on account of their high reactivity). Of these, $\mathrm{Mo}\left[\mathrm{T} p \mathrm{OCH}_{3} \mathrm{PC} \mathrm{Cl}_{2}\right.$ is a known compound and the similarity of the spectral profiles and extinction coefficients strongly indicated an analogous formulation for the other compounds. Gratifyingly, the spectra indeed exhibited dramatic substituent-induced shifts of the Soret maximum (Fig. 6). As shown in Table 1, the Soret maxima of the $\mathrm{MoCl}_{2}$ complexes redshift by $37 \mathrm{~nm}$ between $\mathrm{X}=\mathrm{CF}_{3}$ and $\mathrm{X}=\mathrm{OCH}_{3}$, while the $\mathrm{Q}$ maxima remain essentially unchanged. The Soret maxima of the MoO series, in contrast, are known to be invariant with respect to the substituent $\mathrm{X}^{50}$

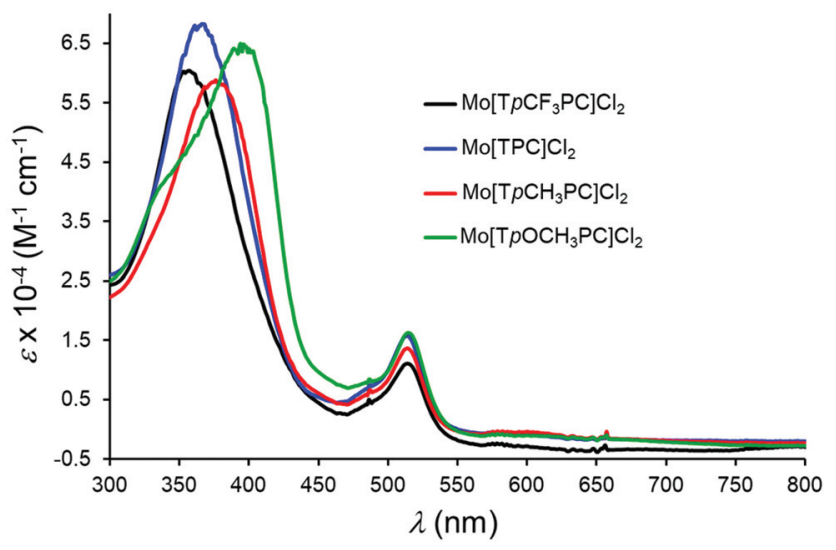

Fig. 6 UV-vis spectra of $\mathrm{Mo}[\mathrm{TpXPC}] \mathrm{Cl}_{2}$, where $\mathrm{X}=\mathrm{CF}_{3}, \mathrm{H}, \mathrm{CH}_{3}$ and $\mathrm{OCH}_{3}$, in dry dichloromethane.

Table 2 In situ UV-vis absorption data for Mo[TpXPC]Cl 2

\begin{tabular}{lll}
\hline & \multicolumn{2}{l}{$\lambda_{\max }\left[\mathrm{nm}, \varepsilon \times 10^{-4}\left(\mathrm{M}^{-1} \mathrm{~cm}^{-1}\right)\right]$} \\
\cline { 2 - 3 } Compound & \multicolumn{1}{l}{ Soret } & $Q$ \\
\hline $\mathrm{Mo}\left[\mathrm{T} p \mathrm{CF}_{3} \mathrm{PC}\right] \mathrm{Cl}_{2}$ & $357(6.03)$ & $514(1.11)$ \\
$\mathrm{Mo}[\mathrm{TPC}] \mathrm{Cl}_{2}$ & $366(6.08)$ & $513(1.57)$ \\
$\mathrm{Mo}\left[\mathrm{T} p \mathrm{CH}_{3} \mathrm{PC}\right] \mathrm{Cl}_{2}$ & $376(5.87)$ & $514(1.36)$ \\
$\mathrm{Mo}\left[\mathrm{T} p \mathrm{OCH}_{3} \mathrm{PC}\right] \mathrm{Cl} 2$ & $394(6.48)$ & $514(1.62)$
\end{tabular}

\section{Conclusion}

Three lines of evidence - crystallographic and DFT optimized geometries, DFT spin density profiles, and in situ electronic absoprtion spectroscopy - indicate that Viking-helmet $\mathrm{MoCl}_{2}$ triarylcorroles are noninnocent with significant $\mathrm{Mo}^{\mathrm{IV}}$ corrole $^{\cdot 2-}$ character. The crystallographic structure in question, $\mathrm{Mo}\left[\mathrm{T} p \mathrm{OCH}_{3} \mathrm{PC}\right] \mathrm{Cl}_{2}$ (CSD: NEMMAW), exhibits characteristic bond length alternations within and around the bipyrrole part of the molecule. Six different functionals reproduce this geometrical attribute with high fidelity. The six functionals also yield mutually consistent broken-symmetry spin density profiles with characteristic spatial separation of $\alpha$ and $\beta$ spin densities. Finally, the UV-vis optical probe, which has been successfully used to identify ligand noninnocence in $>15$ families of metallocorroles (as well as to rule out ligand noninnocence in another $>20$ families), strongly suggests that $\mathrm{MoCl}_{2}$ triarylcorroles are noninnocent, while the analogous MoO complexes are not. (A family here refers to a series of metallocorroles in which the substituents vary systematically, but the metal and axial ligands, if any, are constant.) In this study, we have not obtained a reliable estimate of the percent radical character of $\mathrm{MoCl}_{2}$ corroles. UV-vis spectral shifts, however, suggest a fairly substantial fraction, on the order of $40 \%$ or so, based on similar shifts observed for $3 \mathrm{~d}$-based noninnocent corroles, ${ }^{22}$ which have been analyzed with CASSCF/DMRG-CASPT2 calculations. ${ }^{27}$ The overall evidence for a noninnocent macrocycle in $\mathrm{MoCl}_{2}$ Viking-helmet corroles, in our opinion, thus, is incontrovertible.

\section{Computational methods}

All DFT calculations were carried out with the ADF 2018 program system. ${ }^{51}$ Relativistic effects were taken into account with the zeroth-order regular approximation $\left(\mathrm{ZORA}^{52-54}\right)$ to the Dirac equation, applied as a scalar correction. Large all-electron ZORA STO-TZ2P basis sets were used throughout. Six exchange-correlation functionals were used: OLYP, ${ }^{55,56}$ OPBE, ${ }^{55,57,58}$ B3LYP (with 15\% Hartree-Fock exchange), ${ }^{56,59,60}$ TPSSH, ${ }^{61}$ OPBE0 (with $25 \%$ Hartree-Fock exchange), ${ }^{58}$ and CAM-B3LYP. ${ }^{62}$ Fine integration meshes and tight convergence criteria were used throughout.

\section{Experimental methods}

\section{In situ UV-Vis measurements}

To a 50-mL round-bottom flask equipped with a stirring bar was added a carefully weighed sample of an MoO triarylcorrole $(\sim 2.5-3.0 \mathrm{mg}$ or $0.004 \mathrm{mmol})$ dissolved in dry dichloromethane $(2.0 \mathrm{~mL})$. The solution was degassed with a flow of argon for five minutes, following which silicon tetrachloride (0.01 $\mathrm{mL}, 0.087 \mathrm{mmol})$, dissolved in dry dichloromethane $(0.5 \mathrm{~mL})$, was added. After stirring for $10 \mathrm{~min}$, the red color of the starting material changed to the light brown color of 
$\mathrm{Mo}[\mathrm{T} p \mathrm{XPC}] \mathrm{Cl}_{2}$, and $\mathrm{UV}$-vis analysis of an aliquot of the reaction mixture proved that the reaction was complete. The reaction mixture was diluted to a known volume for quantitative UV-vis analysis. In view the high reactivity of the products, we assumed complete conversion of the starting materials and the extinction coefficients were calculated based on the mass of the starting materials (Fig. 6 and Table 2).

\section{Notes}

There is no archeological evidence that Vikings used horned helmets similar to those depicted in popular culture. ${ }^{63}$ On the other hand, horned helmets from the Bronze Age (depicted in Scheme 1) have been discovered at Veksø, Denmark. ${ }^{64}$

\section{Conflicts of interest}

There are no conflicts to declare.

\section{Acknowledgements}

This work was supported by the Research Council of Norway (grant no. 262229 to AG), the South African National Research Foundation (grant no. 113327 and 96111 to JC), and the Central Research Fund of the University of the Free State (JC). The High Performance Computing facility of the UFS and the CHPC of South Africa is acknowledged for computer time (JC).

\section{References}

1 C. K. Jørgensen, Coord. Chem. Rev., 1966, 1, 164-178.

2 W. Kaim and B. Schwederski, Coord. Chem. Rev., 2010, 254, 1580-1588.

3 R. Eisenberg and H. B. Gray, Inorg. Chem., 2011, 50, 97419751.

4 J. Rittle and M. T. Green, Science, 2010, 330, 933-937.

5 C. Jung, S. de Vries and V. Schünemann, Arch. Biochem. Biophys., 2011, 507, 44-55.

6 S. K. Singh, J. Eng, M. Atanasov and F. Neese, Coord. Chem. Rev., 2017, 344, 2-25.

7 J.-P. Dognon, Coord. Chem. Rev., 2017, 344, 150-162.

8 G. A. Bailey, J. A. Buss, P. H. Oyala and T. Agapie, J. Am. Chem. Soc., 2021, 143, 13091-13102.

9 E. Steene, T. Wondimagegn and A. Ghosh, J. Phys. Chem. B, 2001, 105, 11406-11413 Erratum: J. Phys. Chem. B 2002, 106, 5312-5312.

10 O. Zakharieva, V. Schünemann, M. Gerdan, S. Licoccia, S. Cai, F. A. Walker and A. X. Trautwein, J. Am. Chem. Soc., 2002, 124, 6636-6648.
11 S. Cai, S. Licoccia, C. D’Ottavi, R. Paolesse, S. Nardis, V. Bulach, B. Zimmer, T. Kh. Shokhireva and F. A. Walker, Inorg. Chim. Acta, 2002, 339C, 171-178.

12 E. Steene, A. Dey and A. Ghosh, J. Am. Chem. Soc., 2003, 125, 16300-16309.

13 F. A. Walker, S. Licoccia and R. Paolesse, J. Inorg. Biochem., 2006, 100, 810-837.

14 S. Ganguly, K. E. Thomas, R. Sarangi and A. Ghosh, Chem. - Eur. J., 2017, 23, 15098-15106.

15 K. P. Caulfield, J. Conradie, H. D. Arman, A. Ghosh and Z. J. Tonzetich, Iron(II) Corrole Anions, Inorg. Chem., 2019, 58, 15225-15235.

16 J. Krzystek, A. Schnegg, A. Aliabadi, K. Holldack, S. A. Stoian, A. Ozarowski, S. D. Hicks, M. M. Abu-Omar, K. E. Thomas, A. Ghosh, K. P. Caulfield, Z. J. Tonzetich and J. Telser, Inorg. Chem., 2020, 59, 1075-1090.

17 P. Schweyen, K. Brandhorst, M. Hoffmann, B. Wolfram, M.-K. Zaretzke and M. Bröring, Chem. - Eur. J., 2017, 23, 13897-13900.

18 R. Padilla, H. L. Buckley, A. L. Ward and J. Arnold, J. Porphyrins Phthalocyanines, 2015, 19, 150-153.

19 K. E. Thomas, A. B. Alemayehu, J. Conradie, C. M. Beavers and A. Ghosh, Acc. Chem. Res., 2012, 45, 1203-1214.

20 A. Ghosh, Chem. Rev., 2017, 117, 3798-3881.

21 S. Nardis, F. Mandoj, M. Stefanelli and R. Paolesse, Coord. Chem. Rev., 2019, 388, 360-405.

22 S. Ganguly and A. Ghosh, Acc. Chem. Res., 2019, 52, 20032014.

23 S. Ganguly, L. J. McCormick, J. Conradie, K. J. Gagnon, R. Sarangi and A. Ghosh, Inorg. Chem., 2018, 57, 96569669.

24 H. Vazquez-Lima, H. K. Norheim, R. F. Einrem and A. Ghosh, Dalton Trans., 2015, 44, 10146-10151.

25 H. K. Norheim, J. Capar, R. F. Einrem, K. J. Gagnon, C. M. Beavers, H. Vazquez-Lima and A. Ghosh, Dalton Trans., 2016, 45, 681-689.

26 M. H. Rahmann, M. D. Ryan, H. Vazquez-Lima, A. Alemayehu and A. Ghosh, Inorg. Chem., 2020, 59, 32323238.

27 K. Pierloot, Q. M. Phung and A. Ghosh, Inorg. Chem., 2020, 59, 11493-11502.

28 S. Ganguly, H. Vazquez-Lima and A. Ghosh, Chem. - Eur. J., 2016, 22, 10336-10340.

29 S. Ganguly, J. Conradie, J. Bendix, K. J. Gagnon, L. J. McCormick and A. Ghosh, J. Phys. Chem. A, 2017, 121(50), 9589-9598.

30 W. R. Osterloh, V. Quesneau, N. Desbois, S. Brandès, W. Shan, V. Blondeau-Patissier, R. Paolesse, C. P. Gros and K. M. Kadish, Inorg. Chem., 2020, 59, 595-611.

31 S. Ganguly, D. Renz, L. J. Giles, K. J. Gagnon, L. J. McCormick, J. Conradie, R. Sarangi and A. Ghosh, Inorg. Chem., 2017, 56, 14788-14800.

32 I. H. Wasbotten, T. Wondimagegn and A. Ghosh, J. Am. Chem. Soc., 2002, 124, 8104-8116.

33 M. Bröring, F. Bregier, E. C. Tejero, C. Hell and M. C. Holthausen, Angew. Chem., Int. Ed., 2007, 46, 445-448. 
34 A. B. Alemayehu, L. K. Hansen and A. Ghosh, Inorg. Chem., 2010, 49, 7608-7610.

35 S. Berg, K. E. Thomas, C. M. Beavers and A. Ghosh, Inorg. Chem., 2012, 51, 9911-9916.

36 K. E. Thomas, I. H. Wasbotten and A. Ghosh, Inorg. Chem., 2008, 47, 10469-10478.

37 K. E. Thomas, J. Conradie, L. K. Hansen and A. Ghosh, Eur. J. Inorg. Chem., 2011, 1865-1870.

38 I. K. Thomassen, L. J. McCormick and A. Ghosh, ACS Omega, 2018, 3, 5106-5110.

39 K. E. Thomas, N. S. Settineri, S. J. Teat, E. Steene and A. Ghosh, ACS Omega, 2020, 5, 10176-10182.

40 H. Lim, K. E. Thomas, B. Hedman, K. O. Hodgson, A. Ghosh and E. I. Solomon, Inorg. Chem., 2019, 58, 67226730 .

41 A. B. Alemayehu, K. E. Thomas, R. F. Einrem and A. Ghosh, Acc. Chem. Res., 2021, 54, 3095-3107.

42 A. B. Alemayehu, L. J. McCormick, K. J. Gagnon, S. M. Borisov and A. Ghosh, ACS Omega, 2018, 3, 9360-9368.

43 A. B. Alemayehu, H. Vazquez-Lima, C. M. Beavers, K. J. Gagnon, J. Bendix and A. Ghosh, Chem. Commun., 2014, 50, 11093-11096.

44 P. Schweyen, K. Brandhort, R. Wicht, B. Wolfram and M. Bröring, Angew. Chem., Int. Ed., 2015, 54, 8213-8216.

45 K. E. Thomas, H. Vazquez-Lima, Y. Fang, Y. Song, K. J. Gagnon, C. M. Beavers, K. M. Kadish and A. Ghosh, Chem. - Eur. J., 2015, 21, 16839-16847.

46 R. Sarangi, L. J. Giles, K. E. Thomas and A. Ghosh, Eur. J. Inorg. Chem., 2016, 3225-3227.

47 I. Luobeznova, M. Raizman, I. Goldberg and Z. Gross, Inorg. Chem., 2006, 45, 386-394, DOI: 10.1021/ic051483g.

48 A. E. Meier-Callahan, H. B. Gray and Z. Gross, Inorg. Chem., 2000, 39, 3605-3607.
49 A. Garai, S. Sobottka, R. Schepper, W. Sinha, M. Bauer, B. Sarkar and S. Kar, Chem. - Eur. J., 2018, 24, 1261312622.

50 I. Johansen, H.-K. Norheim, S. Larsen, A. B. Alemayehu, J. Conradie and A. Ghosh, J. Porphyrins Phthalocyanines, 2011, 15, 1335-1344.

51 G. T. Velde, F. M. Bickelhaupt, E. J. Baerends, C. F. Guerra, S. J. A. van Gisbergen, J. G. Snijders and T. Ziegler, J. Comput. Chem., 2001, 22, 931-967.

52 E. van Lenthe, E. J. Baerends and J. G. Snijders, J. Chem. Phys., 1993, 99, 4597-4610.

53 E. van Lenthe, E. J. Baerends and J. G. Snijders, J. Chem. Phys., 1994, 101, 9783-9792.

54 E. van Lenthe, A. Ehlers and E. J. Baerends, J. Chem. Phys., 1999, 110, 8943-8953.

55 N. C. Handy and A. J. Cohen, Mol. Phys., 2001, 99, 403-412.

56 C. Lee, W. Yang and R. G. Parr, Phys. Rev. B: Condens. Matter Mater. Phys., 1988, 37, 785-789.

57 J. P. Perdew, M. Ernzerhof and K. Burke, J. Chem. Phys., 1996, 105, 9982-9985.

58 M. Swart, A. W. Ehlers and K. Lammertsma, Mol. Phys., 2004, 102, 2467-2474.

59 A. D. Becke, Phys. Rev. A, 1988, 38, 3098-3100.

60 P. J. Stephens, F. J. Devlin, C. F. Chabalowski and M. J. Frisch, J. Phys. Chem., 1984, 98, 11623-11627.

61 J. Tao, J. P. Perdew, V. N. Staroverov and G. E. Scuseria, Phys. Rev. Lett., 2003, 91, 146401.

62 T. Yanai, D. P. Tew and N. C. Handy, Chem. Phys. Lett., 2004, 393, 51-57.

63 H. Hencken, The Earliest European Helmets: Bronze Age and Early Iron Age. Harvard University, Cambridge, MA, 1971, 220 pp.

64 H. Norling-Christensen, Acta Archaeol., 1946, 17, 99-115. 